\title{
Dynamics of the Vegetation Landscapes of the Mbere Valley's National Park and Its Southern Periphery
}

\author{
Narke Jean Cyrille ${ }^{1}$ Aoudou Doua Sylvain² \\ ${ }^{1}$ National Institute of Cartography (NIC), Yaoundé, Cameroon \\ ${ }^{2}$ Higher Institute of the Sahel (HIS), University of Maroua, Maroua, Cameroon \\ Email:cyrille_narke@yahoo.fr, aoudoudoua@yahoo.fr
}

How to cite this paper: Cyrille, N.J. and Sylvain, A.D. (2017) Dynamics of the Vegetation Landscapes of the Mbere Valley's National Park and Its Southern Periphery. Open Journal of Ecology, 7, 392-405. https://doi.org/10.4236/oje.2017.76028

Received: March 16, 2017

Accepted: June 26, 2017

Published: June 29, 2017

Copyright $\odot 2017$ by authors and Scientific Research Publishing Inc. This work is licensed under the Creative Commons Attribution International License (CC BY 4.0).

http://creativecommons.org/licenses/by/4.0/

\section{(c) (i) Open Access}

\begin{abstract}
The present study is about the dynamics of the vegetation landscapes of the Mbere Valley's National Park and its southern periphery (MVNP). The physical and human characteristics of this area, translated by an intertwining of natural, anthropic and institutional factors, predispose its vegetation cover to a dynamic which can be progressive or regressive according to the dominant factor. The present study aims at reconstituting the various space-time variations of the MVNP vegetation cover and its periphery between 1987 and 2014, and at determining the processes and the factors having supported these space-time variations of vegetation cover. The methodological step consists of an association of fieldwork and remote sensing in order to characterize the vegetation cover, to reconstitute the evolution of the vegetation cover and to determine the main factors of the processes of this evolution or dynamic. The diachronic analysis shows that the dynamics of the vegetation cover was marked by a progressive evolution between 1987 and 1999, and a regressive evolution between 1999 and 2014. On the base of fieldwork observations and the socio-economic surveys, it arises that the dynamics of the vegetation cover of the valley of Mbere and its periphery is subjected to the combined influence of the natural conditions, from the recurring anthropic disturbances as well as the weight of regulatory measures.
\end{abstract}

\section{Keywords}

Dynamics, Landscapes Vegetations, National Park, Periphery, Mbere Valley

\section{Introduction}

The Mbere Valley's National Park (MVNP) and its southern periphery (Figure 1) are the theatre of several environmental, economic and social stakes responsible 


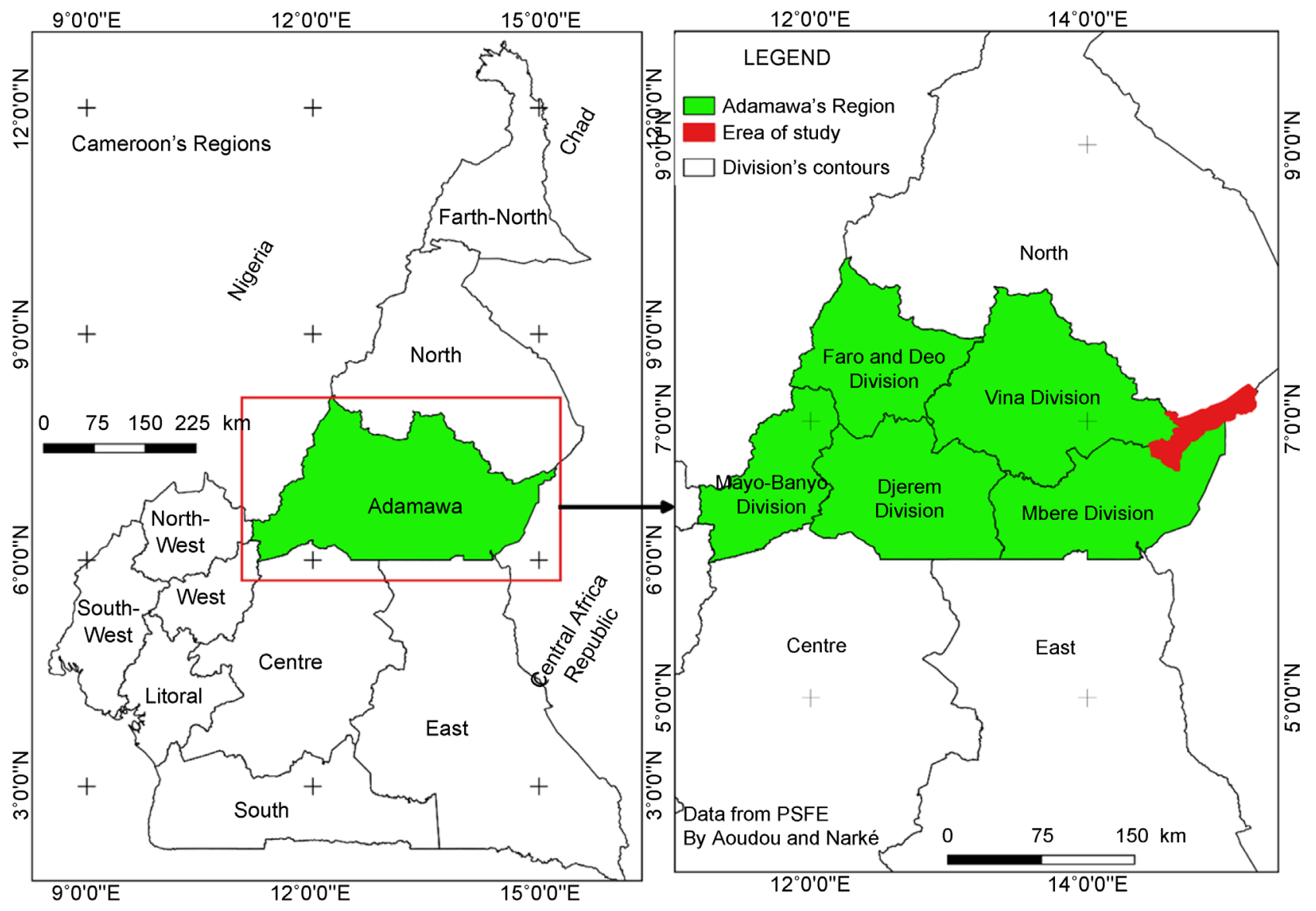

Figure 1. Localization of the study zone.

for the modification of its vegetation cover. At the environmental level, it is marked by the degradation and the invasion of the herbaceous cover by Bokassagrassa or Chromolaenaodorata; the degradation of the pastures due to an intensification of transhumance; the progressive dynamics of timber; the disappearance of wildlife.

From the economic point of view, the MVNP is the attic of the neighboring populations; it is an anagro-pastoral area which is therefore coveted at the same time by the farmers for agricultural practices such as the culture of the tobacco which is the greatest source of income for the inhabitants followed by the collection of the NTFP, the cultivation of maize, hunting, fishing, etc...the qualitative and quantitative abundance of the pasture and the presence of many rivers attract a great number of stockbreeders. At the social level, the area of study is marked by a strong demographic growth following the mass arrival and installation of approximately 17,000 refugees from central african republicin Borgop, village located at the periphery of MVNP ( $2 \mathrm{~km}$ of the protected surface). Within the framework of this study, we focus on the southern periphery with the villages located near the MVNP on the junction Djohong-Yamgba (Figure 2) and which carry out their activities more or less thanks to it. The dynamics of vegetation cover refers to the successions in space and time of vegetal formations which can be observed at various scales [1]. Thus, the characterization of the dynamics of 


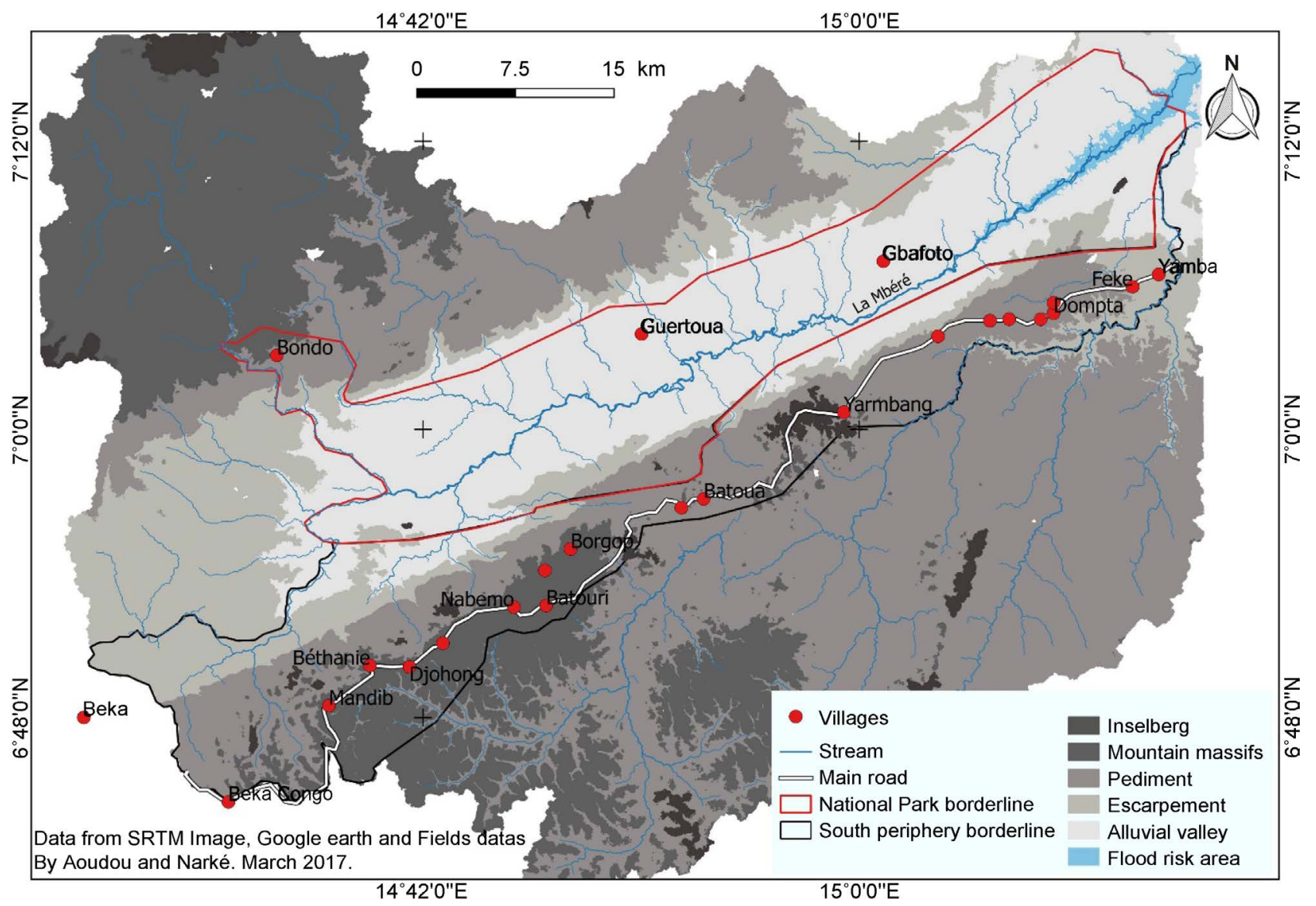

Figure 2. Geomorphological profile of the area of study.

the vegetation cover enables us to release two main trends: the progressive trend and the regressive trend. The availability of the satellite images, notably the sensors lands at 8 , offers the opportunity to follow the space-time modifications of the vegetation cover of the NPMV and its southern periphery. Due to the absence of specialized tools for space management, remote sensing is presented as a means of identifying and monitoring changes in the vegetation cover [2].

The main goal of this work is to reconstitute the dynamics of plant landscapes (space organization and the vegetable composition of each type of vegetation compared to the unit) of the MVNP and its southern periphery between 1987 and 2014, and to determine the factors as well as the processes of these dynamics. From the satellite images of 1987, 1999 and 2014, we highlighted the successive stages of the vegetation cover for each one of these dates. The diachronic study of the occupation of the soil from these multi dates documents allowed us to analyze and assess quantitatively the evolution of the occupation of the soil between 1987 and 2014. This analysis was updated and supplemented thanks to the fieldwork based on the observations of soil, floristic data.

\section{Context of the Study}

\subsection{Study Area}

Located at an altitude of $1300 \mathrm{~m}$ between $06^{\circ} 95^{\prime}$ and $07^{\circ} 2^{\prime}$ north latitude and 
$14^{\circ} 01^{\prime}$ and $14^{\circ} 08^{\prime}$ east longitude, the VMPN (Figure 1 ) located in the region of Adamaoua, More specifically in the department of Mbere, Djohong district. It was created by decree $\mathrm{N}^{\circ}$ 2004/0352/PM of 04/02/2004 [3]. The Mbere Valley National Park is a protected area of wildlife and has the following objectives: to preserve the functions of water towers recognized in the region of Adamaoua for the southern part of Cameroon, as well as the particular landscape and picturesque valley of the Mbere valley; to ensure the continuity and flow of the Mbere River; consolidate the national network of protected areas in Cameroon; to promote the development of ecotourism in order to contribute to the improvement of the living conditions of the riparian populations; to safeguard the habitat of certain species such as hippopotami, buffalo and mountain Redunca [3]. It covers a surface of 77,760 ha and is located in the eponym valley which constitutes the natural prolongation of the Adamaoua plateau. Its relief is not very hilly however it has summits. It is characterized by a wet tropical climate of altitude characterized by two seasons of unequal importance; a short dry season which goes from November to May and a long rainy season for the remaining part of the year. Annual precipitations vary between 1000 and $1300 \mathrm{~mm} / \mathrm{an}$. The vegetation formation of our study area is Sudano-Guinean savanna of altitude. Our zone of study is subjected to the influence of many rivers: the Mbere which is the main river, Ngou, Bouy and Koudini.

\subsection{Remote Sensing as a Tool for the Evaluation of the Dynamics of Vegetation Cover}

We generally need floristic statements or flora surveys in order to characterize vegetation cover; they make it possible to identify the various types of vegetation formations met, to index the various species which compose them (family, kind, species) and to describe them (size, a number, distribution...) [4]. However, for a study on the characterization of the dynamics of vegetation cover, we cannot limit ourselves to the floristic surveys which present only the current situation of the vegetation; thus to evaluate wide landscapes and also to know its previous situation, we are obliged to use remote sensing [5]. The latter enables us to evaluate the dynamics of the vegetation in the fields of slow changes in the structure of vegetation cover (modification of the rate of coverage of a layer of vegetation). This will result in establishing the chart of occupation of the soil; thus the types of occupation of the soil will be characterized and better described according to the floristic survey's data. Therefore, the complexity and diversity of spectral signatures due to the influence of geographic position, plant species, plant factors, atmospheric factors, require us to take account of the data from the floristic surveys in order to avoid any Possible confusion between plant units and better characterize the evolution which also depends on the type of plant formation and the type of species.

\section{Tools and Methods}

The principal data source used for this work is the data set resulting from the 
satellite image processing. In order to refine the quality of the results obtained at the end of the satellite data processing, we made recourse to the floristic data and the data resulting from socio-economic investigations.

\subsection{Floristic Data}

The spot surveys carried out throughout the study area allowed us to identify and individualize the land use classes with very similar spectral signatures; we projected the GPS points from our field surveys on the Landsat images used to map the vegetation cover of our study area. This allowed us to identify and characterize each of these areas of interest by referring to a specific type of land use.

\subsection{The Data Images}

The data images relate to the set of satellite images used for the cartography of the types of occupation of the soil and the description of the successive states of vegetable cover for each appointed date. The processing of the image data allowed us to detect the changes and to reconstruct the dynamics of the vegetation cover of the MVNP and its periphery between 1987 and 2014. For the cartography and the follow-up of the dynamics of the vegetation cover between 1987 and 2014, we chose the three dates images because of the duration necessary for the follow-up of the dynamics of savannas and the availability of the images. Two Landsat 5 TM scenes of November 1987, two Landsat 7 ETM + scenes of March 1999, and two Landsat 8 OLI scenes of February 2014 with coordinates Path 183 to 184 and Row 55.The period of acquisition of these images corresponds to the dry season and has the advantage of allowing a differentiation of the plant formations whose discrimination seems very difficult during the rainy season when the soil is more or less completely covered. The processing of image data was organized in three phases: pre-processing operations, numerical classification and description of changes in land use.

\section{1) Pre-treatment Operations}

Image pre-processing or preliminary analysis is a set of operations whose purpose is to increase the readability of the data in order to facilitate their interpretation [6]. This step consisted in identifying the tools that allow us to locate and to highlight the types of land use and then to represent the occupation of the soil in different classes. In order to be able to read the images and decide on various land use classes, we used two types of approach, namely the analogue approach and the digital approach. To distinguish the shades of vegetation, we selected bands 3, 4 and 5 for Landsat OLI images and bands 2, 3 and 4 for Landsat TM and ETM+. We made a traditional colorful composition in 4-3-2 [7]. The definition and categorization of land use classes was based on the correlation between the spectral signature of terrestrial objects and our knowledge of the terrain. From this method, we distinguish: forests galleries, clear forests, wooded savannas or timbered savannas, savannas trees, shrubby savannas, grassy savannas and/or easily flooded meadows, water and "burning" as well as the bare soil and sand bank. 


\section{2) Supervised Classification of the images}

The numerical classification of images consists in grouping groups of similar pixels into classes. In order to identify and individualize land cover classes with very similar spectral signatures, we have projected the GPS points obtained from our field surveys on the Landsat image used to map the vegetation cover of our zone Of study. These GPS points projected on the image allowed us to define the training plots and record the spectral signature of each of these plots before proceeding to the supervised classification. For these classifications, we have chosen the method by a maximum probability which allows classifying the elements of an image as a function of an approximation of the spectral signatures of the pixels.

\section{3) Post-processings}

This step allowed us to highlight the changes in land use. More precisely, the different land-use classes obtained by classification have been transformed into polygons under Envi 4.5 and then imported into QGis 2.18. These layers of information obtained are complemented by information extracted from exogenous data such as the road network and the localities. The queries and spatial analyzes are then carried out to answer specific questions related to the central question of research. Finally, the cards are produced.

\section{Results}

\subsection{States of Occupations of the Soil in 1987, 1999 and 2014}

The results of classifications of the various images used enabled us to draw up the state of occupation of the soil of the MVNP and its southern periphery for each one of these dates, to quantify the occupation of the soil and to highlight the influence of vegetation cover.

\section{1) The state of the occupation of the soil in 1987}

The cartography of the occupation of the soil in 1987 shows that the dominant vegetation formation are the tree savannas with $692,283.6$ hectares that are $39.67 \%$ of the total surface of the zone of study. It is followed by shrubby and grassy savannas which cover a surface of $369,796.5$ hectares that is $21.19 \%$ of the total surface. Wooded savannas come in third position and cover a surface of $229,519.8$ i.e. $13.15 \%$ of the total surface of the VMPN and its periphery. Then we have the clear forests or woodland ecotone with a surface of 206,819.1 hectares i.e. $11.85 \%$. Finally for the covered zones we have the forests galleries with $123,517.8$ hectares i.e. $7.08 \%$. Non-covered zones represented by the class of water and burning $(58,258.8$ hectares) and the class of bare soil (65,077.2 hectares) occupy $07.07 \%$ of the total surface of the MVNP and its periphery. The predominance of the woody elements is explained by a strong regeneration of the ligneous family as well as the growth of the pastures. The Figure 3 presents the state of the occupation of the soil of the MVNP and its southern periphery in 1987.

\section{2) The state of the occupation of the soil in 1999}

The examination of Table 1 one shows that for the occupation of the soil in 1999 (Figure 4), the dominant vegetation formation is the clear forest or woodland ecotone with $603,250.2$ hectares that is $34.56 \%$ of the total surface of the 


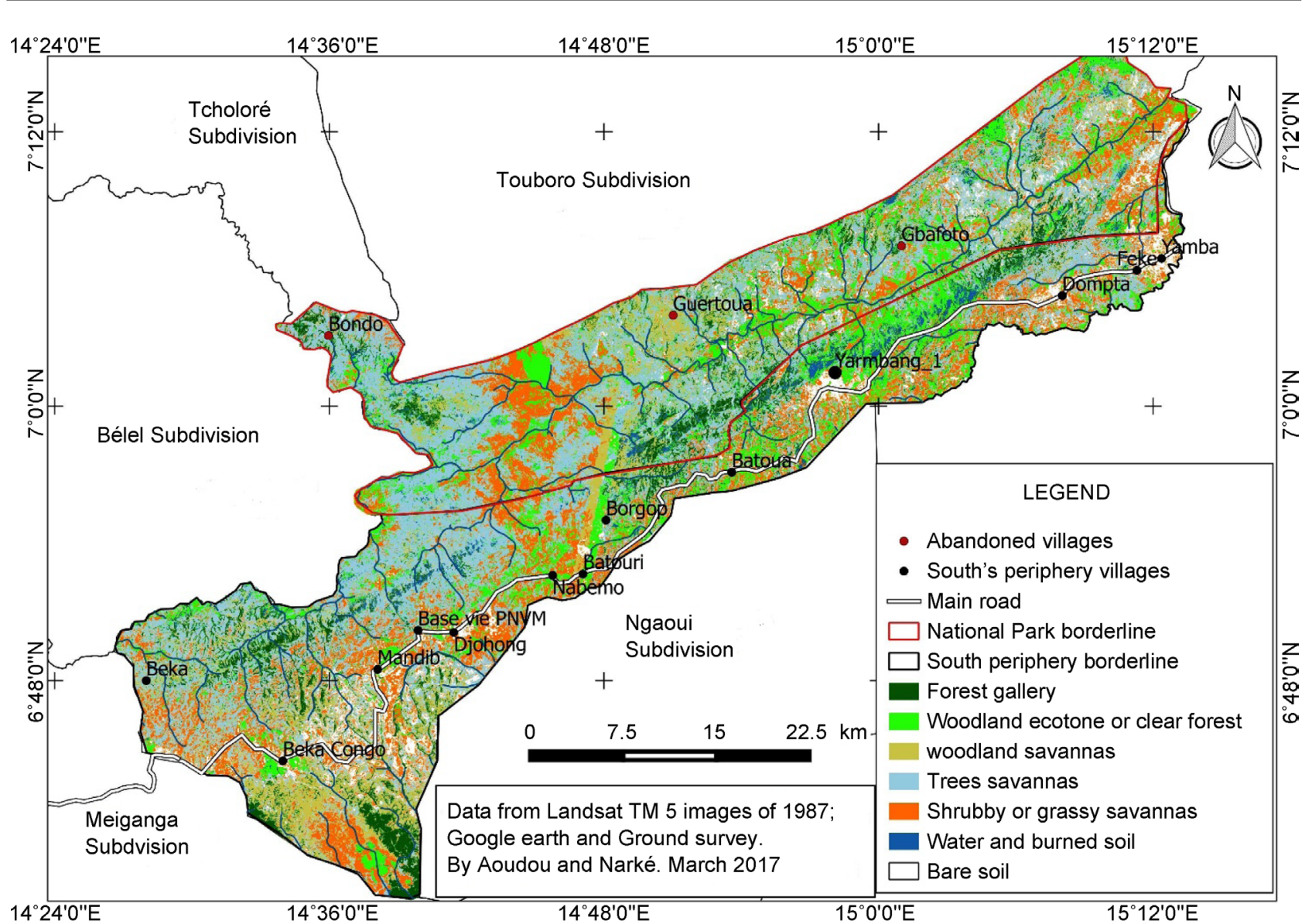

Figure 3. Chart of occupation of the zone of study in 1987.

Table 1. Evolution of the occupation of the soil of the PNVM and its southern periphery in 1987, 1999 and 2014.

\begin{tabular}{cccccccc}
\hline & \multicolumn{2}{c}{1987} & & \multicolumn{2}{c}{1999} & \multicolumn{2}{c}{2014} \\
\hline Occupation of the soil & Surface (Ha) & $\%$ & Surface (Ha) & $\%$ & Surface (Ha) & $\%$ \\
\hline Forest gallery & $123,517.8$ & 7.08 & $234,639.9$ & 13.44 & $17,392.23$ & $9.97 \%$ \\
Woodland or Clear forest & $206,819.1$ & 11.85 & $603,250.2$ & 34.56 & $43,821.18$ & $25.11 \%$ \\
Wooded savannas & $229,519.8$ & 13.15 & $266,726.7$ & 15.28 & $23,705.1$ & $13.58 \%$ \\
Trees savannas & $692,283.6$ & 39.67 & $248,794.2$ & 14.26 & $18,215.01$ & $10.44 \%$ \\
Shrubby and grassy savannas & $369,796.5$ & 21.19 & $143,379.9$ & 8.22 & $59,671.62$ & $34.19 \%$ \\
Water and Burned soil & $65,077.2$ & 3.73 & $146,273.4$ & 8.38 & 1164.6 & $0.67 \%$ \\
Bare soil & $58,258.8$ & 3.34 & $102,208.5$ & 5.86 & $10,557.54$ & $6.05 \%$ \\
Total & $1,745,272.8$ & 100 & $1,745,272.8$ & 100 & $174,527.28$ & $100.00 \%$ \\
\hline
\end{tabular}

zone of study. It is followed wooded savannas which cover a surface of 266,726.7 hectares is $15.28 \%$ of the total surface. Tree savannas come in third position and cover a surface of $248,794.2$ i.e. $14.26 \%$ of the total surface of the valley of Mbere and its periphery. Then we have the forests galleries with a surface of 234,639.9 hectares i.e. $13.44 \%$. Shrubby savannas $(77,805$ hectares) and grassy savannas (65,574.9 hectares) occupy $08.22 \%$ of the total surface of the studied zone. Water and burning $(102,208.5$ hectares $)$ as well as the bare soil (146,273.4 hectares) 


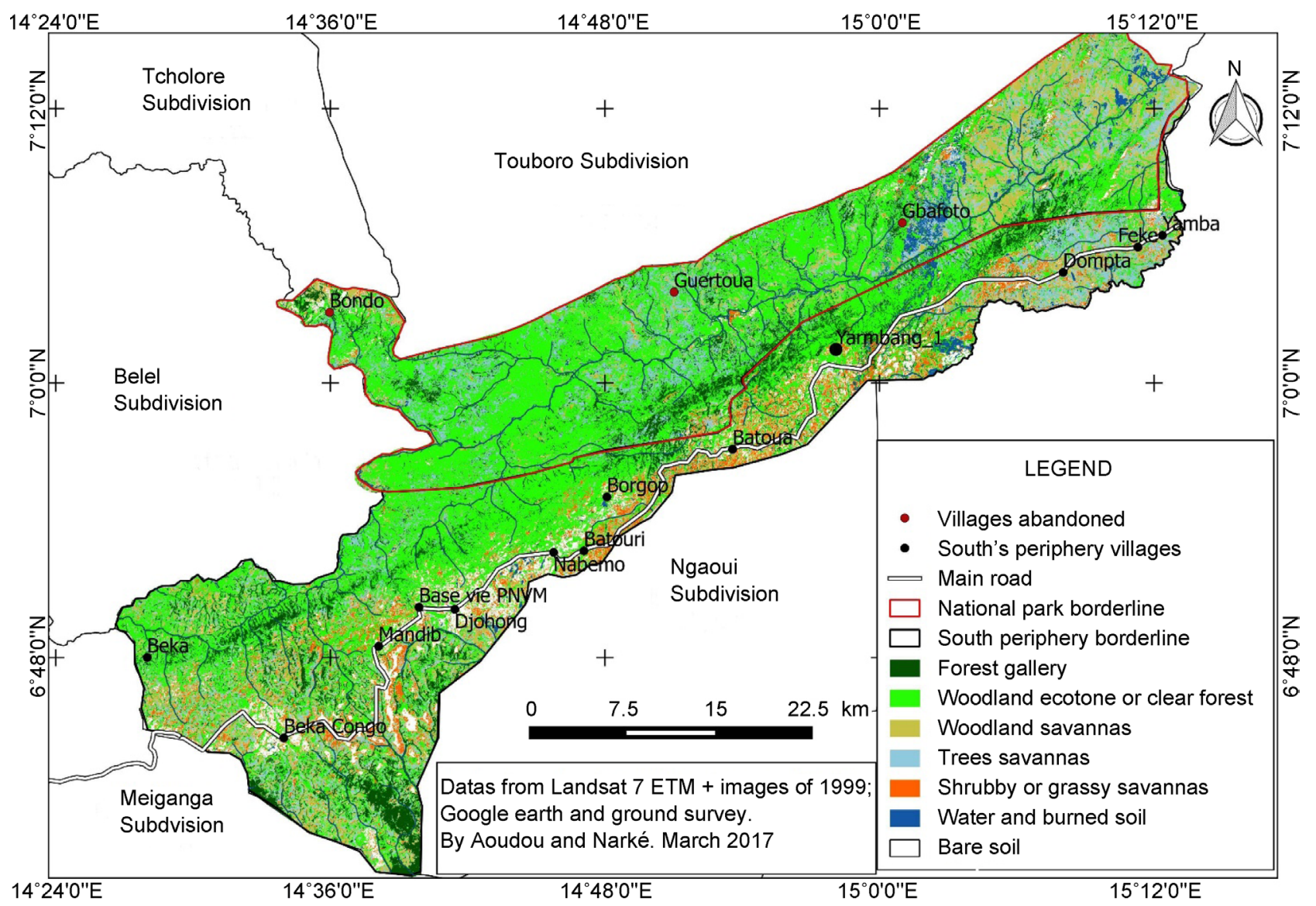

Figure 4. Chart of occupation of the zone of study in 1999.

occupy $14.24 \%$ of the total surface of the framework of study. The forests cover a surface of $837,890.1$ hectares i.e. $48.00 \%$ of the total surface of the studied zone. Indeed, with the invasion of the pastures by Chromolaenaodorata as from the Seventies, the settings in defense of the soil, the abandonment of the zone by stockbreeders in order to flee the African "trypanosomiasis", one witnessed a strong colonization of the ligneous family and the transition from savannas formations to the forests formations. This situation leads at the same time to the contracting of the savannas formations.

\section{3) The state of the occupation of the soil in 2014}

As far as the occupation of the soil in 2014 (Figure 5) is concerned, the dominant vegetation formation is the clear forest or woodland ecotone with a surface of $43,821.18$ hectares that is $25.11 \%$ of the total surface of the area of study. It is followed by the shrubby savanna which covers a surface of $34,155.54$ hectares that is $19.57 \%$ of the total surface. Grassy savannas come in third position and occupy a surface of $25,516.08$ hectares i.e. $14.62 \%$ of the total surface of the MVNP and its southern periphery. Then we have the timbered savannas with a surface of 23,705.1 hectares i.e. 13.58\%. Wooded savannas are followed by trees savanna which cover a surface of $18,215.01$ hectares is $10.44 \%$. Finally for the covered zones, we have the forests galleries which occupy 17,392.23 hectares of the total surface is a percentage of $9.97 \%$. The class of water and burning (1164.6 


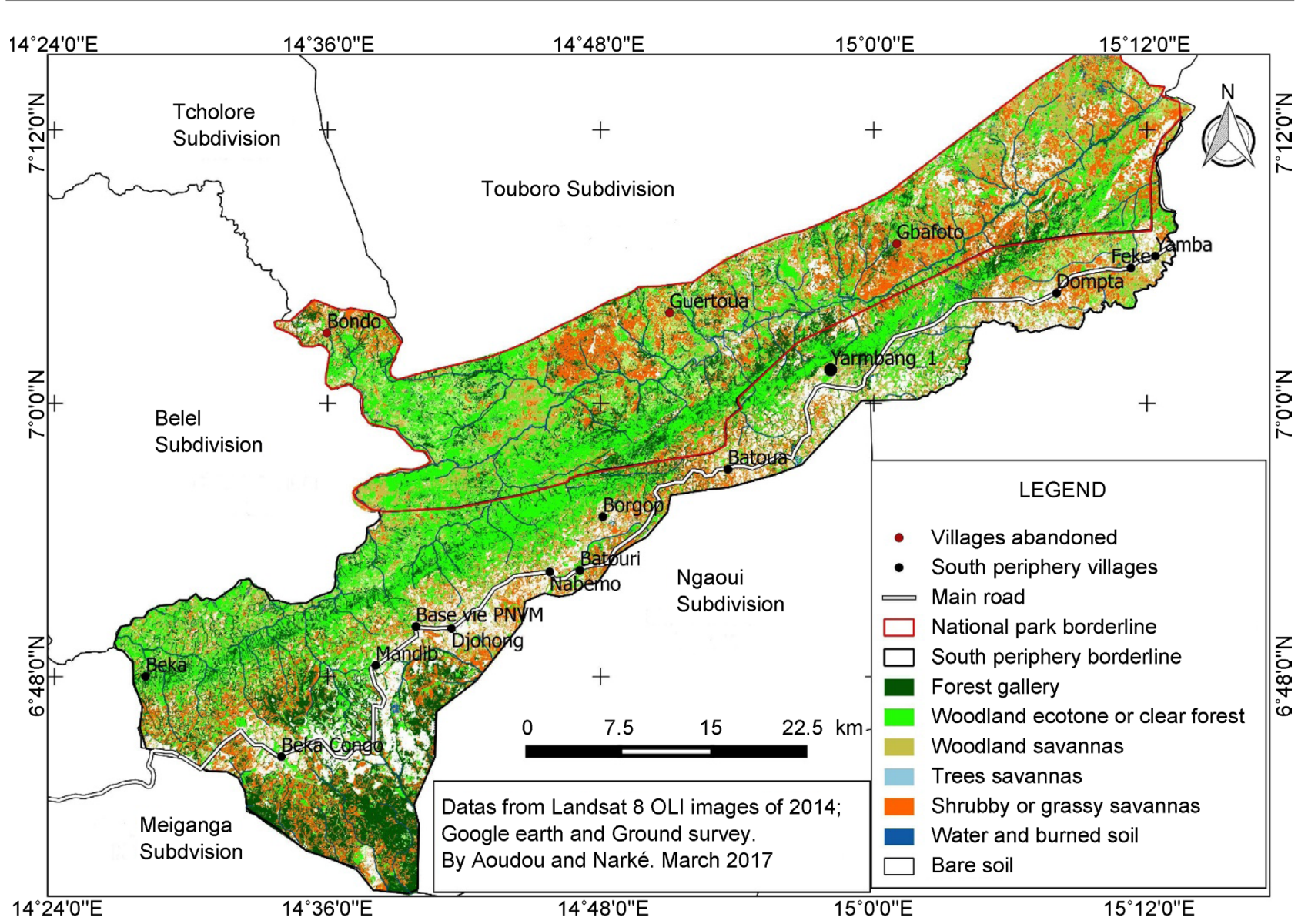

Figure 5. Chart of occupation of the zone of study in 2014.

hectares) and bare soil class (10,557.54 hectares) representing the non-covered zones, cover $06.72 \%$ of the total surface of the MVNP and its periphery.

\subsection{Various Phases of the Dynamics of Vegetation Cover}

The follow-up of the eight (8) classes of occupation of the soil retained thanks to the Landsat images of 1987, of 1999 and 2014 enabled us to highlight the main trends of the dynamics of the vegetation landscape of the MVNP and its southern periphery.

\section{1) The progressive phase between 1987 and 1999}

The crossing of the occupation of the soil of 1987 with that of 1999 enables us to detect some perceptible variations on the level of the classes of occupation of the soil. This phase is marked by the transition of the savannas formations towards the formation of forests. It is the case of the forests galleries which occupied a percentage of $07.08 \%$ in 1987 and which in 1999 passes to $13.44 \%$. The clear forests in the same way in 1987 occupied $11.85 \%$ of the total surface of the zone and passed in 1999 to $34.56 \%$ of the total surface. The intermediate formations (wooded savannas) beside the closed formations also knew an evolution. Indeed, wooded savannas of which the percentage of occupation of the evaluated soil with $13.15 \%$ passed to $15 \%$ and $28 \%$ in 1999 is an evolution of $2.13 \%$. One can notice also the regression of savannas in particular trees savanna and grassy 
shrubby savannas. Trees savanna which were in 1987 the most abundant vegetation formations with a percentage of $39.67 \%$ and in 1999 they were estimated at $14.26 \%$ that is a loss of $25.41 \%$ of its surface. Following trees savanna, we have grassy shrubby savannas where the percentage of soil occupation in 1987 was $21.19 \%$, and who in 1999 do not cover that $8.22 \%$ are a loss of $12.97 \%$ of its surface. The progressive dynamics of the formation of forests as well as the regressive dynamics of the savanna trees to the profit of the formations of clear forests were already announced at the time of our exploratory investigations through expressions like: “lédédjaftiguénê, “djontadôlédédoudibouriguéne”" . Figure 6 presents the evolution of the classes of occupation of the soil between 1987 and 1999.

Several factors explain this progressive dynamics of vegetation cover, in particular the transition of the formations of savannas towards the formations of forests. It is notably the defense waves for the restoration and the protection of the pastures that started from the 70s (defense band of $6 \mathrm{~km}$ along the Gandinang-Djohongroad in 1955 and that of 1960 along the Yarbang-Yamgba road and the defense for the creation of the MVNP in 2004 [8]. These defenses favored the growth and the reforestation of the zone of study. Moreover in 1985, the head of the sector in charge of breeding had already signaled the critical degradation of the pastures notably the advanced growth the pastures.

\section{2) The regressive phase between 1999 and 2014}

Between 1999 and 2014 we notice the regressive phase. It is about the extension of the space influence of shrubby savannas and grassy savannas. Indeed, between 1999 and the 2014 open formations tripled their space influence; they

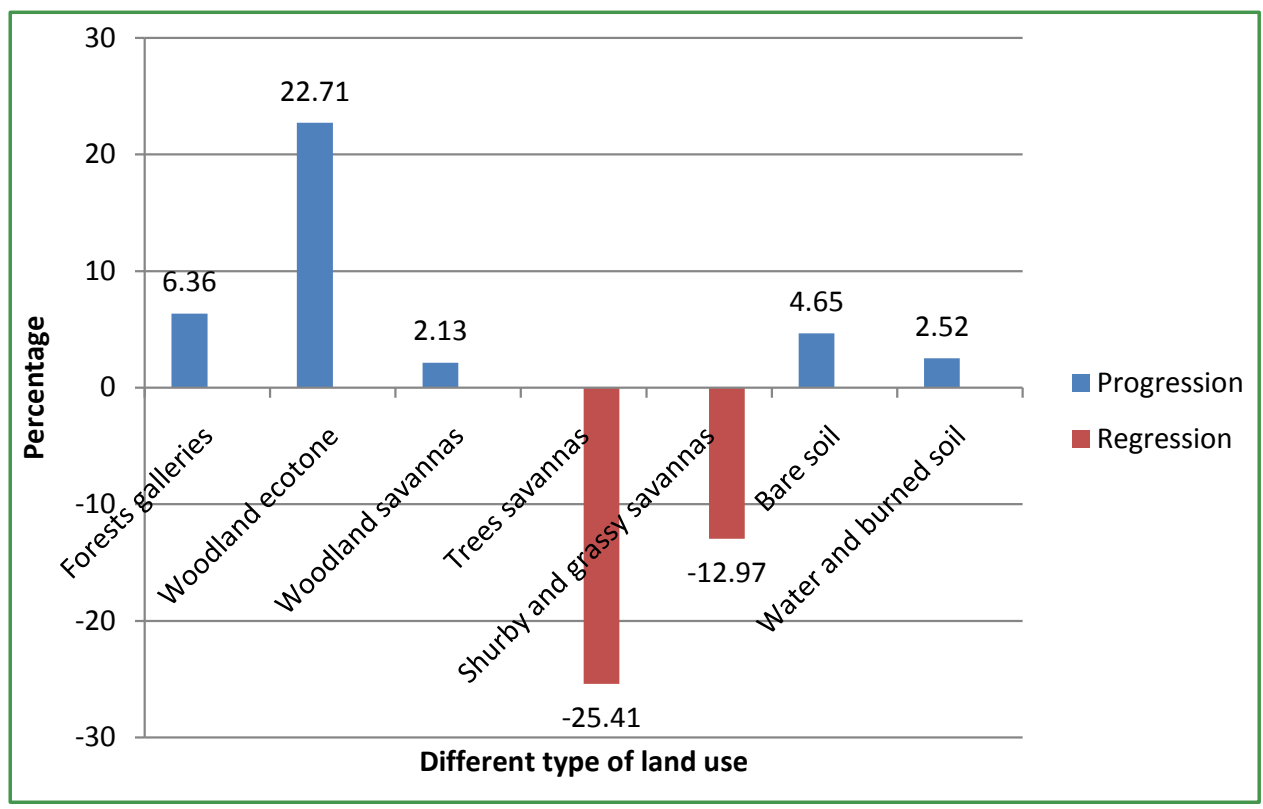

Figure 6. Evolution of the classes of occupation of the soil between 1987 and 1999. (Source: image processing)

${ }^{1}$ In fufuldé meaning: "the ligneous family colonized the herbaceous ones", "nowadays the ligneous family are more abundant than the herbaceous ones compared to the past years". 
passed from $08.22 \%$ to $24.19 \%$ of occupation of the total surface of the MVNP and its periphery that is an increase of $15.97 \%$. But for the closed formations, they passed from $48,00 \%$ of occupation of the total surface of the zone of study to $35.07 \%$ is a loss of $12.93 \%$. The intermediate formations passed from 29 , $02 \%$ of occupation of the soil of the total surface of the framework of study to $24.02 \%$ and $02 \%$ is a loss of $05.52 \%$. Regressive dynamics supported the extension of the space influence of shrubby savannas and grassy savannas to the detriment of wooded savannas and savanna trees. Figure 7 presents the evolution of the occupation of the soil between 1999 and 2014 .

This regressive phase is explained by the strong anthropic pressure through agriculture and the breeding; the arrival as well as the installation of almost 17,000 Central African refugees in the Djohong council; wood cuts by the stockbreeders for the construction of vast closed areas and the opening of vast fodder fields; the strong use of bush fires that are not controlled by the farmers, the bee-keepers and the stockbreeders whose contribution in the regression of the formations of savannas is significant. There is also the exploitation of the logs for the construction of houses and public works as well as the manufacture of arts objects (mortars, bench, armors).

From Figure 8, it appears that the most outstanding evolution relates to the regression whose rate of evolution amounts to $45.12 \%$. It is followed by progressive dynamics with an evaluated rate of evolution of $31.90 \%$. Lastly, also let us note that some vegetation covers of the zone of study estimated at $22.98 \% \mathrm{kept}$ their space influence. Thus it undoubtedly appears that the regression of vegetation cover is much more significant than its extension.

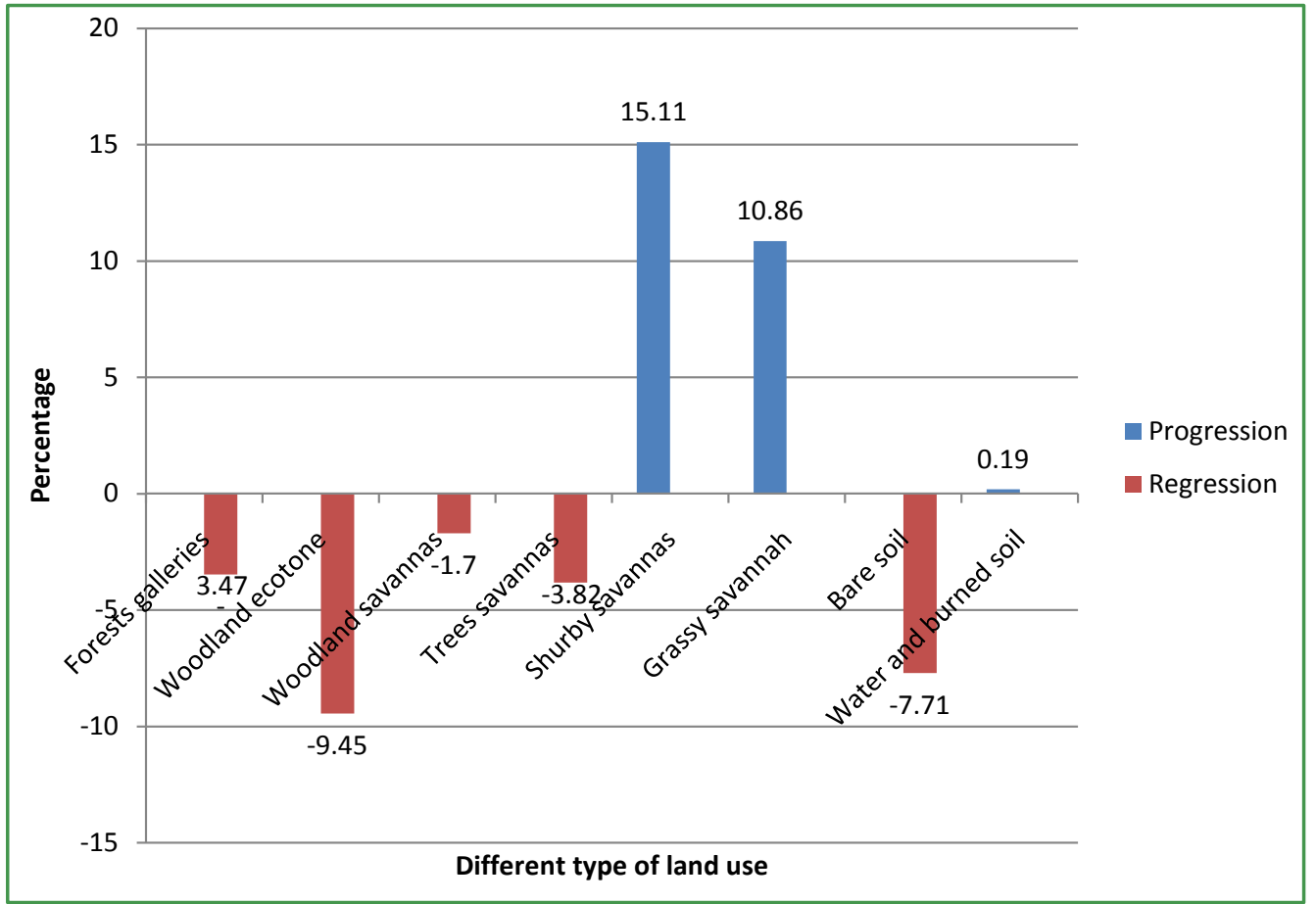

Figure 7. Evolution of the class S of occupation of the soil between 1999 and 2014. (Source: image processing) 


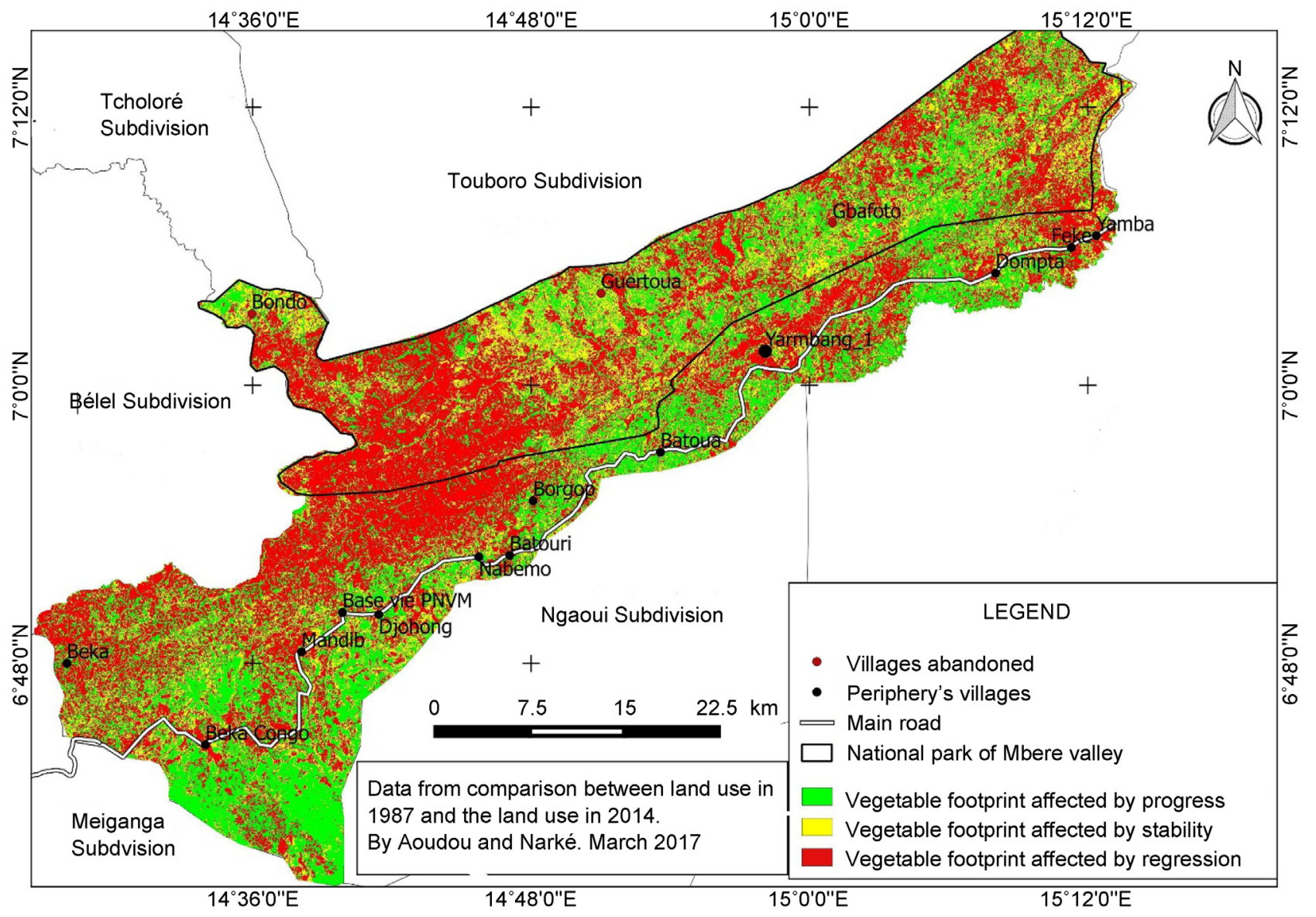

Figure 8. Changes of vegetation cover between 1987 and 2014.

\section{Interpretation}

The prevalence of narrow vegetation formations (clear forests galleries, forests and wooded savannas) through the thickening of the ligneous family is also explained by the low anthropic pressure on the woody elements inside the valley of Mbere. Indeed, the strong repression exerted by the agents of the service for the conservation of the aforementioned protected surface, very broken topography and the difficulty of access in the MVNP limits certain anthropic activities such as the exploitation of logs in the forest galleries and clear forests, the wood cuts. Moreover, the predominance of shrubby savannas and grassy savannas on savanna trees are explained by the strong anthropic pressure through the agriculture which remains the principal source of income from the great majority of the population. It is the case of Tobacco which is mainly cultivated along the Mbere river whose influence on space is observed by the degradation of the forest galleries and the colonization of space along the Mbere river through the predominance of grassy savannas along this river. Burning shows the pressure made by sheperd who use fire in order to renew their pastures, destroying glossines.

Moreover, the strong anthropic pressure is also explained by the increase in the local population and the installation of the Central African Republic refugees in Borgop located at the periphery of the Park $(2 \mathrm{Km})$. This situation leads to an abuse and uncontrolled of the vegetation resources and consequently the degra- 
dation of the vegetation cover following the increase in the demand for firewood which remains the main source of domestic energy for $95 \%$ of the population, the extension of the zones of cultures, the intensification of the practice of bush fires, the degradation of the pastures, and the destruction of the forest galleries and clear forests for the needs of service and log which were more accentuated with the proliferation of the chainsaws.

But the breeding involved also the degradation of herbaceous cover following the pressure made on the pastures, the uncontrolled use of bush fires and the colonization of the forest by Chromolaenaodorata. Let us also note that the strong proportion of the bare soil is also related to the season of frame grabbing which is the dry season, supports an exaggeration of this class. In 1987, the formations of savannas (timbered savannas, savanna trees and grassy shrubby savannas) are most dominant and cover a surface of 1,291,599.9 hectares i.e. $74.01 \%$ of the total surface of the studied zone. According to the work of Letouzey (1969) [9], the Adamaoua region was covered with more than $90 \%$ of shrubby or clear savanna trees with Danielliaoliveri and Lophira lanceolata. Our results obtained on the proportion of savannas corroborate those of Letouzey. This predominance is explained by a strong regeneration of the woody elements as well as growth of the pastures. The phases for setting defense of the soil to the periphery of the valley of Mbere that happened as from the 70s [8].

The dynamics of the vegetation landscapes of the MVNP and its periphery is not a dynamic in a general way; this evolution does not affect the totality of vegetation cover but it relates to the various types of occupation of the soil. Therefore, the whole vegetation formations of the zone of study does not have the same evolution in time and space, but that of the great types of vegetation formations which are inter alia the narrow formations (forests galleries, clear forests), intermediate formations (wooded savannas and savanna trees) and open formations (shrubby savannas and grassy savannas). Ultimately, the vegetation cover was in general influenced by a progressive trend marked by a strong thickening of woody cover and by a regressive trend whose context is related to invasion then to the replacement of herbaceous cover by Chromolaenaodorata.

\section{Conclusion}

This work concerned the dynamics of the vegetation cover of the MVNP and its southern periphery between 1987 and 2014. The fieldwork and the analysis of the multi dates satellite images enabled us to present the successive states of the vegetation for each appointed date, to release the main trends of the dynamics of vegetation cover between these dates and to determine the factors of these dynamics. Moreover, the dynamics of the vegetation cover of the Mbere valley and its southern periphery between 1987 and 2014 is marked by two main trends: The progressive trend of 1987 to 1999 and the regressive trend of 1999 to 2014 . On the one hand, we observe a strong colonization of the medium by ligneous family and Chromolaenaodorata. In addition, there is a degradation of the herbaceous cover. The dynamics of the vegetation cover in the MVNP is subjected 
to the combined influence of the natural conditions (climate, presence of the glossines), recurring anthropic disturbances (bush fires, overgrazing, the increase of population, selective cuts by defect of the ligneous family log) as well as the measurements (the setting of defense as from the seventies for the restoration and the protection of the pastures, the passage of the pipeline by the Mbere valley, the creation of the MVNP in 2004).

\section{References}

[1] Mbamba Mbamba, J.P.K and Kadiri, S.B. (2012) Forêts à l'assaut des savanes en Afrique centrale: Dynamique de la flore ligneuse de l'écotone forêt-savane dans le Parc national du Mbam et Djerem au Cameroun. Editions universitaires européennes, Saarbrücken.

[2] Tabopda, G.W. (2008) Les aires protégées de l'Extrême-Nord Cameroun: entre politiques de conservation et pratiques locales. Ph.D. Thesis, Université d'Orléans, Orléans.

[3] Issouf, B., et al. (2010) Anthropisation et dynamique spatio-temporelle de paysages forestiers en République Démocratique du Congo. Ph.D. Thesis, Université libre de Bruxelles, Brussels.

[4] DFAP/ MINEF (2006) Rapport des missions de prospection de l'équipe WWF/PSSN dans l'Adamaoua Camerounais, pour une contribution à l'élaboration d'une stratégie de conservation de la biodiversité. TchabalMbabo.

[5] Jacquin, A. (2010) Dynamiue de la végétation de savanes en lien avec l'usage des feux à Madagascar. Ph.D. Thesis, University of Toulouse, Toulouse.

[6] Sylvain, A.D. (2010) Suivi de l'évolution de la végétation ligneuse de la savane soudanienne dans haute vallée de la Bénoué au Nord-Cameroun. Ph.D. Thesis, Université de Ngaoundéré, Ngaoundéré.

[7] Nguedjo, P. (2013) Utilisation de la télédétection et des systèmes d'information géographique pour l'analyse des feux de brousse et l'évaluation de la dynamique du couvert végétal dans le parc national du Mpem et Djim et sa zone périphérique au Cameroun. Master's Thesis, Université de Liège, Liège.

[8] Douffissa, A. (1993) L'élevage bovin dans le Mbere (Adamaoua-Cameroun). Collection Etudes et theses, Editions de l'ORSTOM, 274 p.

[9] Prospère, N.T. (2013) Spatialisation du risque de transmission des trypanosomiases bovines dans le bassin versant de riga (Adamaoua). Master's Thesis, University of Ngaoundéré, Ngaoundéré. 
Submit or recommend next manuscript to SCIRP and we will provide best service for you:

Accepting pre-submission inquiries through Email, Facebook, LinkedIn, Twitter, etc. A wide selection of journals (inclusive of 9 subjects, more than 200 journals)

Providing 24-hour high-quality service

User-friendly online submission system

Fair and swift peer-review system

Efficient typesetting and proofreading procedure

Display of the result of downloads and visits, as well as the number of cited articles Maximum dissemination of your research work

Submit your manuscript at: http://papersubmission.scirp.org/

Or contact oje@scirp.org 